\title{
Study on Constructing a Vocational Education Strategy System of Diversified New Generation Migrant Workers'
}

\author{
Yanli Fu \\ Jilin Engineering Normal University, Changchun, Jilin, 130000
}

Keywords: diversified education training system, new generation migrant workers

\begin{abstract}
The new generation of migrant workers is not only an important force in the development of rural economy, but also an effective force in the construction of a socialist harmonious society. The vocational education status of the new generation of migrant workers directly affects their quality level and ability. New rural construction, rural urbanization development, rural economic progress and social occupational evolution will inevitably lead to the dynamic changes of the new generation of migrant workers' professional quality and ability structure. The healthy growth of the new generation of migrant workers needs a stable professional quality and ability structure basis. According to the main characteristics and outstanding problems of the new generation of migrant workers' vocational education, combined with the inherent rules and essential requirements of the new generation of migrant workers' vocational education, the corresponding strategy system should be constructed to give full play to the vocational education to improve the professional quality and ability of the new generation of migrant workers, and the role of effectively solving the problems existing in the vocational education of the new generation of migrant workers, and ensuring the effective development and continuous operation of the new generation of migrant workers' vocational education.
\end{abstract}

\section{Introduction}

What is the new generation of migrant workers, the relevant scholars have defined: the migrant workers who went out to work in the early 1980s as the first generation of migrant workers, the migrant workers who went out to work in the early 1990s as the new generation of migrant workers, and further pointed out that the new generation of migrant workers Most of them go out to work directly, basically they have not engaged in agricultural work, and they have not even basic knowledge about farming. [2] We believe that the new generation of migrant workers mainly refers to the collective name of the young farmers who were born in 1980 and who first went out to work and do business after the 1990s. The formulation of the new generation of migrant workers is relative to the first generation of migrant workers. It is based on the significant differences in the age, education background, motivation, identity, and career expectations of the new generation of migrant workers.

\section{The dilemma of the new generation of migrant workers' vocational education}

Under the new era, the vocational education of the new generation of migrant workers in China has not yet met the needs of its group. The key point is that the supply of vocational education does not match the needs of the new generation of migrant workers. Therefore, from the perspective of the supply side, we look at the vocational education of the new generation of migrant workers. We believe that there are certain deficiencies in terms of system, quality and structure. (I) Unreasonable supply of vocational education system China has introduced a series of laws and regulations on the new generation of migrant workers' vocational education, but the educational effect is not satisfactory. The key point is that the supply of vocational education system for the new generation of migrant workers is insufficient. First, the vocational education system of the new generation of migrant workers has not yet been perfected, and the educational effect is not good. Our country's education system is mainly aimed at youth education. Schools are the carrier of their education 
work. The attention of migrant workers is relatively low. The training of new generation of migrant workers has not been fully absorbed into the vocational education system. At present, there are 343 agricultural higher vocational colleges and agricultural-related higher vocational colleges in the country, accounting for only $27 \%$ of the total number of higher vocational colleges in the country, and the distribution is uneven, mostly concentrated in the eastern and central regions [5]. The education of the new generation of migrant workers in China is generally carried out by professional vocational education institutions, but the employment of new generation of migrant workers is more flexible and changeable. The system design of vocational education is continuous and systematic education, which is related to the new generation of farmers. The actual needs of the workers are contrary to each other, and the effect of vocational education is certainly not good. Second, vocational education and qualification certification are not uniform. The vocational education of the new generation of migrant workers in China is completed by the education department, and the certification of vocational qualifications is usually managed by the labor and social security departments. This leads to the completion of vocational education by multiple departments and long-term management. The vocational qualification certificate is the basis for the new generation of migrant workers to participate in their vocational skills and the choice of occupation, but because vocational education and vocational certification are not completed by the same department, resulting in uneven vocational education institutions, professional certification is not standardized, its role is large discount. This not only reduces the social recognition of migrant workers' vocational training, but also affects their enthusiasm for participating in training [6]. Third, there is insufficient funding for vocational education and the number of participants is limited. The new generation of migrant workers' vocational education has public welfare, but the governments at all levels, especially the county-level governments, are obviously insufficiently invested, and there is a phenomenon of misappropriation and borrowing. The enterprises that work for the new generation of migrant workers are not motivated to invest in vocational education because of the consideration of cost reduction. The new generation of migrant workers have limited income, and the cost of education for thousands of dollars is prohibitive. Only relying on the help of the government and enterprises. The lack of funds for vocational education has become a major obstacle to the participation of new generation of migrant workers in vocational education.

The design of vocational education in China is still a traditional educational model. Its educational mode, educational content and educational form are not effectively matched with the needs of the new generation of migrant workers, resulting in a low supply of vocational education. This is also a new generation of migrant workers. One of the reasons for the high level of interest in vocational education, but the actual number is small. First, it is contrary to the professional characteristics of the new generation of migrant workers. The new generation of peasant workers have a long time to work, and the intensity of their work has made it difficult for them to have enough spare time to take the initiative to participate in vocational education. However, the existing vocational education institutions carry out vocational education according to the established working hours or nights. The time of education and the location of vocational education are fixed, which has caused many new generations of migrant workers to have more than enough to participate in vocational education. Second, the content and mode of education are single, and it is difficult to cater to the diverse needs of the new generation of migrant workers. The vocational education of the new generation of migrant workers in China is still a one-way teaching of teachers. The education and training of practical ability is insufficient, and it is difficult to meet the diversified needs of the new generation of migrant workers for occupational adaptation, cultural adaptation, psychological adaptation and development adaptation. Third, the quality of the faculty of vocational education for the new generation of migrant workers needs to be improved. The professional faculty of vocational education is not professional, and the efficiency of education and training is not good. The teachers of vocational education give a theoretical lecture on the vocational education of the new generation of migrant workers, and light practice training. Some vocational education teachers have part-time technicians in the enterprise. Although the practical experience is abundant, the theoretical knowledge is not systematic, the logic ability is not strong, 
etc. The problem is highlighted. The current situation of teachers in vocational education leads to the real dilemma of "the lack of practice of vocational teachers and the lack of theory of skilled personnel".

\section{Constructing a Diversified New Generation Migrant Workers' Vocational Education Strategy}

Play government functions and build a sound policy system. The new generation of migrant workers' vocational education is an important part of coordinating the development of urban and rural vocational education. Since the government is the main body for the development of urban and rural vocational education, it has the most important responsibility for coordinating the development of urban and rural vocational education. Therefore, it is also necessary to vigorously develop the new generation of migrant workers' vocational education. It is the fundamental responsibility and important mission of the government. First of all, the government should incorporate the new generation of migrant workers' vocational education into the planning of regional economic and social development, especially the new generation of migrant workers' vocational education and new rural construction, rural urbanization, and rural economic progress. Strategic planning for vocational education. Secondly, the government should focus on the strategic planning of the new generation of migrant workers' vocational education, combined with the vocational education in the region, and optimize the integration, coordination and unification of educational resources. For areas with shortage of vocational education resources and related conditions, it is necessary to introduce corresponding support. policy. However, the government's responsibilities are not limited to investment. It should also be based on the specific conditions of the new generation of migrant workers in the region and the actual status of the existing vocational education resources, and formulate a plan for the allocation of vocational education resources for the new generation of migrant workers. A long-term mechanism for the use, allocation and sustainable growth of educational resources to ensure the optimal and long-term use of regional vocational education resources. Finally, the government should set up a new generation of migrant workers vocational education leading group, establish member units including relevant functional departments, formulate a new generation of migrant workers vocational education joint meeting system, and hold joint meetings on a regular basis, requiring all functional departments to give full play to the role of the department, Seriously implement the resolutions formed by the joint meeting and report on the progress of the new generation of migrant workers' vocational education in a timely manner.

Highlight the ability and establish a comprehensive education and training system. At present, the new generation of migrant workers need to practice, have theoretical entrepreneurial knowledge, easy to master, quick-starting entrepreneurial skills, low-investment, high-yielding entrepreneurial skills, adapt to strong, resilient high entrepreneurial psychology and small risk, less loss of entrepreneurship Gate. Professional quality and ability are the premise of the employment of new generation of migrant workers. Only by optimizing the structure of professional quality and enhancing the ability of professional competition can we fundamentally change the professional status of the new generation of migrant workers. Guided by the improvement of professional quality and ability, from the perspective of social and economic development, new rural construction and the needs of the new generation of migrant workers, we must reasonably grasp the target system of the new generation of migrant workers' vocational education and realize the diversification of the educational target system; Beginning with the integration of the professional spirit, knowledge, institutional, behavioral and psychological layers, scientifically construct the content system of the new generation of migrant workers' vocational education, and realize the comprehensiveization of the educational content system; from the three-dimensional learning network, The level of training network and the comprehensive education network complement each other, effectively set up the means system of the new generation of migrant workers vocational education, and realize the diversification of educational means system; from government, vocational colleges or training institutions, enterprises and new generation farmers Starting with the relevance of the work, we will 
actively create a four-level educational mechanism to realize the multi-faceted body of the new generation of migrant workers.

Emphasize dynamic operation and build a collaborative career education process. The new generation of migrant workers' vocational education is a dynamic and complex continuous process. In addition to defining educational goals, determining educational content, and choosing educational methods, it is necessary to conduct reasonable educational evaluations. The objective evaluation of education is helpful to analyze the problems existing in the vocational education of the new generation of migrant workers and to grasp the future trend of the development of vocational education for the new generation of migrant workers. First of all, vocational colleges or training institutions must incorporate education evaluation into the new generation of migrant workers' vocational education system, especially combining education evaluation with educational goals, educational content and educational methods, and the new generation of migrant workers' professional quality and ability. The improvement is combined. Secondly, constructing a reasonable evaluation content of education mainly includes the realization of educational goals, the completion of educational content, the grasp of educational priorities, the scientific nature of educational methods, the rationality of educational resource allocation, and the level of educational performance. Thirdly, according to the implementation of the new generation of migrant workers' vocational education and the specific performance of the new generation of migrant workers after receiving vocational education, adhere to the principle of coordination and unification, using employer enterprise units, new generation of migrant workers as the main body of evaluation, and constructing multi-level vocational education evaluation. system. Finally, the results of education evaluation will be announced in time to effectively solve the problems and deficiencies found in the evaluation process, enhance the performance of the new generation of migrant workers' vocational education, and promote the sustainable development of the new generation of migrant workers' vocational education.

\section{Conclusion}

With the development of society, the comprehensive quality of migrant workers, especially the quality of skills, needs to be greatly improved. All localities should fully mobilize the enthusiasm of employers and migrant workers to participate in the vocational education and training of migrant workers, adhere to the market-oriented, rely on enterprises, and aim at employment, highlighting the effectiveness of vocational education and training. Through the development of vocational education for the new generation of migrant workers, vocational skills training, improve the professional knowledge and knowledge content, establish a complete vocational training system, form a new generation of migrant workers vocational education bridge, so that they can learn a skill and obtain corresponding qualifications, Improve their self-esteem and self-confidence to better stimulate their productive potential. In this way, it is not only conducive to the construction of a harmonious society, but also conducive to the stability and development of the country. At the same time, it also lays the foundation for migrant workers to become "social people" beyond the "instincts."

\section{Acknowledgements}

Project Source: “Thirteenth Five-Year” Social Science Project of Jilin Provincial Department of Education

Project Name: Study on the Difficulties and Countermeasures of Vocational Education Training for New Generation Migrant Workers in Jilin Province

Project Number: JJKH2017177SK

\section{References}

[1] Sun Xuemin, Zhu Fengli. Research on Problems and Countermeasures in the Continuing 
Education of New Generation Migrant Workers [J]. Continuing Education Research, 2011(01): 57-59.

[2] Li Yibai. Mobile Learning for the New Generation of Migrant Workers: Status Quo, Demand and Development Strategy [J]. China Distance Education 2010 (09): 37-42.

[3] Zhang Jia, Zhao Baozhu, Investigation on the Status Quo of Vocational Education and Training of New Generation Migrant Workers [J]. Vocational Education Communication, 2011(15): 44-50.

[4] Cai Qian. A Comparative Study of Farmers' Quality and Quality Education at Home and Abroad [J]. Journal of Beijing Radio and Television University 2007(03).

[5] Zhang Zhizeng. Analysis of the new generation of migrant workers vocational education [J]. China Paper Download Center, 2011-11-15. 